AUTHOR CORRECTION

\title{
Author Correction: A nonlinear magnonic nano-ring resonator
}

Qi Wang (D), Abbass Hamadeh (D), Roman Verba, Vitaliy Lomakin, Morteza Mohseni, Burkard Hillebrands (D), Andrii V. Chumak and Philipp Pirro (iD)

npj Computational Materials (2021)7:26 ; https://doi.org/10.1038/s41524-021-00497-6

Correction to: npj Computational Materials https://doi.org/10.1038/ s41524-020-00465-6, published online 14 December 2020.

The original version of this Article incorrectly gave the first address in the list of affiliations as 'Fachbereich Physik, Technische Universitaet Kaiserslautern, Kaiserslautern, Germany', instead of the correct 'Fachbereich Physik and Landesforschungszentrum OPTIMAS, Technische Universität Kaiserslautern, D-67663 Kaiserslautern, Germany'.

Also, Andrii V. Chumak was originally incorrectly associated with 'Institute of Magnetism, Kyiv 03142, Ukraine'.

This has now been corrected in both the PDF and HTML versions of the Article. (c) Open Access This article is licensed under a Creative Commons Attribution 4.0 International License, which permits use, sharing, adaptation, distribution and reproduction in any medium or format, as long as you give appropriate credit to the original author(s) and the source, provide a link to the Creative Commons license, and indicate if changes were made. The images or other third party material in this article are included in the article's Creative Commons license, unless indicated otherwise in a credit line to the material. If material is not included in the article's Creative Commons license and your intended use is not permitted by statutory regulation or exceeds the permitted use, you will need to obtain permission directly from the copyright holder. To view a copy of this license, visit http://creativecommons. org/licenses/by/4.0/.

(c) The Author(s) 2021 